\title{
Identification of rural landscape classes through a GIS clustering method
}

\author{
Irene Diti, Daniele Torreggiani, Patrizia Tassinari \\ University of Bologna, Department of Agricultural Sciences, Bologna, Italy
}

\begin{abstract}
The paper presents a methodology aimed at supporting the rural planning process. The analysis of the state of the art of local and regional policies focused on rural and suburban areas, and the study of the scientific literature in the field of spatial analysis methodologies, have allowed the definition of the basic concept of the research. The proposed method, developed in a GIS, is based on spatial metrics selected and defined to cover various agricultural, environmental, and socio-economic components. The specific goal of the proposed methodology is to identify homogeneous extra-urban areas through their objective characterization at different scales. Once areas with intermediate urban-rural characters have been identified, the analysis is then focused on the more detailed definition of periurban agricultural areas. The synthesis of the results of the analysis of the various landscape components is achieved through an original interpretative key which aims to quantify the potential impacts of rural areas on the urban system. This paper presents the general framework of the methodology and some of the main results of its first implementation through an Italian case study.
\end{abstract}

\section{Introduction and aims}

The actual configuration of the territorial and landscape mosaic is characterized from mixed urban and rural macro-systems that create hybrid spaces with intermediate characteristic. This calls for new methods suitable for classifying rural areas based on their vocations, critical issues and potentials, in order to define consistent evolution scenarios. The relationships between natural and manmade landscape components are widely described in the scientific literature through

Correspondence: Irene Diti, Daniele Torreggiani, Patrizia Tassinari, University of Bologna, Department of Agricultural Sciences, Viale G. Fanin 48, 40127 Bologna, Italy.

E-mail: irene.diti@unibo.it, daniele.torreggiani@unibo.it, patrizia.tassinari@unibo.it

Key words: countryside classification, GIS model, periurban agricultural areas, rural planning.

(C) Copyright I. Diti et al., 2013

Licensee PAGEPress, Italy

Journal of Agricultural Engineering 2013; XLIV(s2):e97

doi:10.4081/jae.2013.s2.e97

This article is distributed under the terms of the Creative Commons Attribution Noncommercial License (by-nc 3.0) which permits any noncommercial use, distribution, and reproduction in any medium, provided the original author(s) and source are credited. the urban footprint (Socco et al., 2004) and ecological footprint (Rees and Wackernagel, 1996). Comprehensive evaluation of the characteristics of rural areas and agricultural activities can lend useful support to urban and landscape planning and rural development policies. Therefore, the goal of the research is to develop an innovative quantitative and multicriteria method aimed at classifying rural areas based on their agricultural, environmental, socioeconomic and landscape profile, referring to an original "Agri-Environmental Footprint" (AEF) postulate. In particular, this research focuses on a methodology for the geographical definition of periurban contexts aimed to support the calibration of policies for the preservation of the agricultural characters of these areas. This is fundamental in order to safeguard the countryside (Tassinari et al., 2007a), as underlined by the European Landscape Convention.

\section{Materials and methods}

The proposed methodology is currently being tested, in order to validate it, on the New District of Imola (Figure 1), a study-area in northern Italy, where several information were already available thanks to previous studies (Tassinari et al. 2007a, 2007b).

Data used in our study consisted in spatial information widely used in planning processes: land use maps, cadastral data, statistical georeferred information. Such databases have been elaborated through ArcMap GIS by ESRI. The indexes have been defined based on a critical analysis of the scientific and technical literature.

\section{Results}

Figure 2 shows the main result of our work, that is the architecture of the multilevel methodological approach for the classification of the countryside.

A first set of indicators is used in the first-level analysis (Overall AEF land Classification) to achieve a preliminary identification of homogeneous extra-urban areas based on the agro-environmental, socio-demographic and infrastructural land's profile. The resulting Rural Land Classes (RLCs) are described and grouped according to their specific characteristics. Intermediate urban-rural areas represent the spatial domain for the second-level analysis (Periurban AEF Land Classification), aimed to identify different typologies of Periurban Land Classes (PLCS), mainly based on their agricultural peculiarities and farm structure.

Some of the indices used in the first level of analysis derive from the fields of Landscape Ecology (as Shannon Entropy Index, Fragmentation Index or Corrected Perimeter-Area Index) and Agronomy (such the Land Suitability), while others were conceived for this methodology, in order to describe the recreational and ecological value of the analized countryside (as the EcologicalRecreational Value that describe the density of natural and protected areas in the case study area) or in 


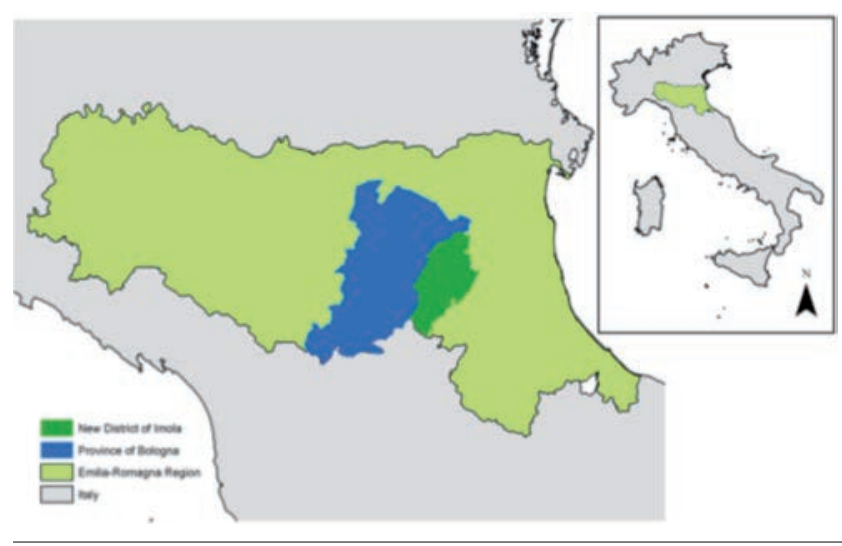

Figure.1. The study area (New District of Imola, Bologna, Italy).

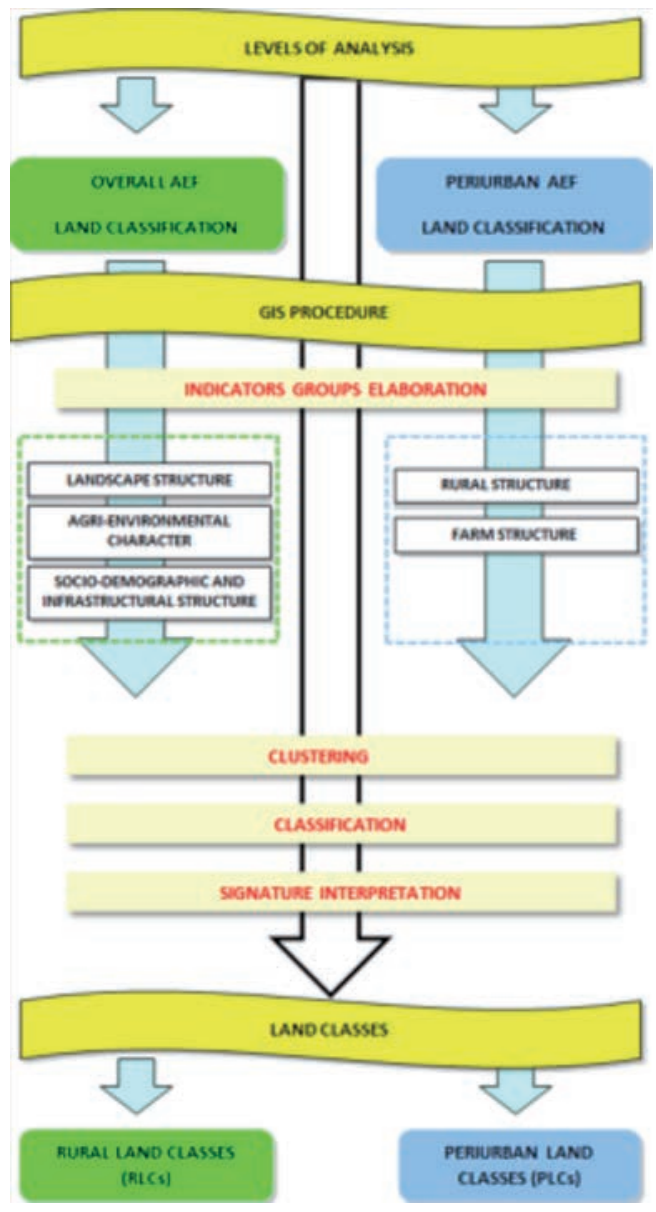

Figure 2. The structure of the model.

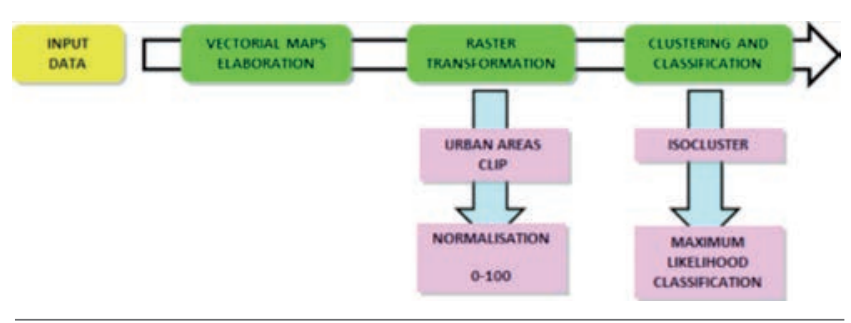

Figure 3. GIS analysis model. order to quantify the presence/absence of agri-environmental CAP measures, or the impact of multifunctional agricultural activities such as holiday or educational farms. Some indexes were designed with the intent of describing the population characteristics (as the Population Density or the Old-Age Index) and the impact of the infrastructure on the open spaces outside the cities (Road density).

At each level of the analysis vector maps (made for each indicator analized) were converted to raster maps and elaborated to obtain multilevel raster maps that were analysed through suitable cluster analysis algorithms to identify the main landscape patterns (Figure 3 ).

This GIS procedure and interpretation of the signature of each cluster resulting from the analyses carried out on the study area allowed us to define three landscape classes:

High nature value areas with mainly extensive farming system Areas with a significant agricultural matrix

Areas with a significant agricultural matrix and remarkable urbanrural interference

The last one represents the spatial domain for the second-level analysis (Periurban AEF Land Classification), allowing to identify "periurban agricultural areas" where agricultural characters and high farming potentiality prove more relevant.

\section{Conclusions}

The main strength of the proposed methodology is that of consisting in a systematic and objective procedure that allows to analyze intact multi-thematic data and to aggregate them without any a priori assumption or reclassification filter typical of overlay zoning procedures. This method can be implemented in the land analysis process to support local authorities in spatial planning decisions.

Furthermore, starting from the same general land classification of the first AEF level, the iterative analysis process at the second level of analysis can be used also to identify other specific homogeneous areas using different sets of variables.

Future in-depth studies and applications will mainly focus on the calibration and selection of most important and influential indicators through the comparison of the results obtained from the application of the methodology to different geographical contexts.

\section{References}

Rees, W., Wackernagel, M. 1996. Urban ecological footprints. Why cities cannot be sustainable and why they are a key to sustainability. Environment Impact Assess Rev, 16, 223-248.

Socco C. (ed.),2007. Il manuale urbanistico invisibile. La sintassi della città disgregata, Working Paper 06/07.

Tassinari, P., Torreggiani, D., Benni, S. 2007a. Agriculture and Development Processes: Critical Aspect, Potential and Multilevel Analysis of Periurban Landscapes. Part I, E-Journal - CIGR, 9,1-14.

Tassinari, P., Torreggiani, D., Benni, S. 2007b. Agriculture and Development Processes: Critical Aspect, Potential and Multilevel Analysis of Periurban Landscapes. Part II, E-Journal - CIGR, 9,1-21- 